\title{
Multiple system inflammatory syndrome associated with SARS-CoV-2 infection in an adult and an adolescent
}

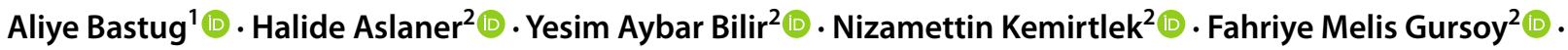 \\ Serdal Bastug ${ }^{3}$ [D $\cdot$ Hurrem Bodur ${ }^{1}[$
}

Received: 5 February 2021 / Accepted: 10 March 2021 / Published online: 19 March 2021

(c) The Author(s), under exclusive licence to Springer-Verlag GmbH Germany, part of Springer Nature 2021

\begin{abstract}
Multisystem inflammatory syndrome in adults (MIS-A) is a new syndrome related with COVID-19. A case-based review was performed to present real-life experiences in terms of main findings and treatment options. We described two cases with the diagnosis of MIS and searched the literature to review all reported $\geq 18$-year-old cases. The PubMed, Scopus, and Web of Science databases were searched. All relevant articles from January 2020 to February 2021 were reviewed. An adolescent and an adult patient (18 and 40 years-old, respectively) with the diagnosis of MIS were presented. Both had the consistent clinical findings with the case definition criteria. Although steroid, intravenous immunoglobulin (IVIG) and supportive care treatments have been suggested in the literature, there exists no treatment guideline for MIS-A. The clinical and laboratory findings of the patients progressively improved with the implementation of the IVIG and the pulse steroid treatments. A total of 51 cases ( $\geq 18$ years-old) with MIS were analyzed. Mean age was $29.4 \pm 10$ years. Fever $(80.4 \%)$, gastrointestinal (72.5\%), and respiratory symptoms $(54.9 \%)$ were the predominant symptoms. Cardiovascular abnormalities were the most frequent reported findings $(82.4 \%, 42 / 51)$. The dermatological and conjunctival findings were reported in $39.2 \%$ and $35.3 \%$ of the patients, respectively. The increased level of inflammatory biomarkers was remarkable. Most of the patients were treated successfully with steroid and IVIG. Clinicians managing adult patients should keep in mind the development risk of MIS related with SARS-CoV-2 infection to perform necessary interventions properly without delay. IVIG and pulse steroid treatments are the effective options on clinical improvement.
\end{abstract}

Keywords Multisystem inflammatory syndrome $\cdot$ MIS-A $\cdot$ Pulse steroid $\cdot$ IVIG $\cdot$ COVID-19

\section{Introduction}

COVID-19-related multisystem inflammatory syndrome (MIS) has been reported in children (MIS-C) and rarely in adults (MIS-A) since April and June 2020, respectively.
Since the clinical characteristics of MIS-C are similar to Kawasaki disease, it was defined initially as a Kawasaki-like illness. Thereafter, a prominent increase was observed in the number of MIS-C reports worldwide. After the reports of cases similar with MIS-C in adults, which was named

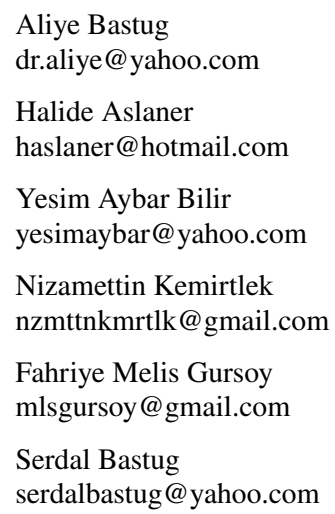

Hurrem Bodur

hurrembodur@gmail.com

1 Department of Infectious Disease and Clinical Microbiology, University of Health Sciences Turkey, Ankara City Hospital, 1604. Street, No: 9, 06800 Çankaya/Ankara, Turkey

2 Department of Infectious Disease and Clinical Microbiology, Ankara City Hospital, 06800 Ankara, Turkey

3 Department of Cardiology, Yildirim Beyazit University, Ankara City Hospital, 06800 Ankara, Turkey 
as MIS-A, the accumulation of data has been increasing. Although the underlying immunopathology is not well defined, adaptive immunity is thought to be responsible [1]. The fever is the main finding of the syndrome and gastrointestinal, cardiovascular, hematological, and dermatological findings are the predominant ones. MIS should be kept in mind in a patient with recent COVID-19 infection and presenting findings and laboratory abnormalities indicating hyper inflammation (such as elevated ferritin, C-reactive protein (CRP), d-dimer and lymphocytopenia). The treatment options recommended for MIS-C include high-dose steroid and intravenous immunoglobulin (IVIG) [2]. There are case definitions and center-specific treatment protocols, but there exists no widely accepted guideline especially for MIS-A [3, 4]. However, the same treatment modalities have been reported to be used successfully for MIS-A in previous reports. As the SARS-CoV-2 pandemic is currently quite effective and involves increasing number of people around the world, it is important to introduce clinical findings based on real-life experiences regarding the ways to manage these cases.

In this case-based review, we present the two cases of COVID-19-associated MIS in an adult and an adolescent. In addition, literature search was performed to analyze the main findings of MIS reported in $\geq 18$-year-old adolescents and adults. It was aimed to increase the awareness of the clinicians providing care to adults and to propose treatment modalities to be used in this new emergent syndrome.

\section{Case 1}

A 40-year-old male patient presented to the Emergency Department (ED) with the complaint of high fever in November 2020. He had a fever, diarrhea, and abdominal pain for the previous 4 days. He had COVID-19 23 days ago. He was admitted to the Infectious Disease Clinical ward for further investigation and treatment. On physical examination, he had a $39^{\circ} \mathrm{C}$ fever, tachypnea, tachycardia, skin rash, and abdominal tenderness. Nasopharyngeal swab samples were tested for SARS-CoV-2 PCR yielded negative results, and blood samples tested for SARS CoV2- IgM + IgG antibody yielded positive results (Table 1). Laboratory analysis revealed the followings: leukocytosis, neutrophilia, lymphopenia, elevation in liver function tests, D-dimer, troponin, $\mathrm{N}$-terminal pro-B-type natriuretic peptide (pro-BNP), ferritin, fibrinogen, $\mathrm{C}$-reactive protein (CRP), procalcitonin, and IL-6 (Table 2). Chest computed tomography (CT) was normal. Abdominal CT revealed a small amount of effusion, mesenteric adenopathy, and inflammation in the intestine and mesentery. Abdominal CT findings were interpreted as terminal ileitis. Echocardiography was performed since he had persistent fever, tachypnea, and tachycardia. Increased cardiac wall thickness, mild global hypokinesis, and minimal pericardial effusion were the pathologic findings of echocardiography. Ejection fraction (EF) was $45 \%$ (Table 2). The diagnosis of MIS-A was considered primarily, but blood, urine, throat, and stool samples were obtained to exclude other possible causative infectious agents. Since he had a high level of procalcitonin with the other indicators of inflammation, the possible causative bacterial agents could not be excluded until the culture results were obtained. Hence, ceftriaxone and vancomycin therapy was started to cover potential causative agents. On the physical and radiological examination and with the results of basic laboratory tests, we could not find any focus for infection. When evaluated with the history of COVID-19 in the previous 3 weeks, MIS-A was strongly considered as the possible diagnosis. Therefore, pulse methylprednisolone $1 \mathrm{gr} / \mathrm{per}$ day for 3 days, intravenous immunoglobulin (IVIG) $20 \mathrm{gr} / \mathrm{per}$ day for 5 days, and anticoagulant therapy with low molecular weight heparin were given without waiting for the results of other laboratory tests. On the second day of treatment, the fever of the patient regressed, and laboratory abnormalities started to improve. After the implementation of $1 \mathrm{~g}$ methylprednisolone therapy for 3 days, its dose was reduced and completed to 10 days $(80 \mathrm{mg} /$ day for 3 days, then $40 \mathrm{mg} /$ day for 4 days). The antibiotics were discontinued on the fifth day as there was no growth in the cultures. Echocardiography was performed again at the end of the treatment. It was observed that the pericardial effusion regressed and the EF increased to $60 \%$. The clinical and laboratory findings of the patient improved and he was discharged fully recovered. On the post- discharge follow-up (on day 15 after discharge), the patient did not have any symptoms and findings.

\section{Case 2}

An 18-year-old female patient was admitted to the ED with fever, chills, abdominal pain, and dyspnea, which had been ongoing for four days. She had COVID-19 about 2 months ago. She was admitted to the Infectious Diseases Clinic for advanced diagnosis and treatment. On physical examination, she had $38{ }^{\circ} \mathrm{C}$ fever, pulse rate $110 / \mathrm{min}$, blood pressure 70/40 $\mathrm{mmHg}$, and abdominal tenderness. Laboratory analysis revealed leukocytosis, neutrophilia, lymphopenia, and high levels of D-dimer (1.9 mg/L), CRP (245 g/L) and procalcitonin $(1.53 \mu \mathrm{g} / \mathrm{L})$.

Nasopharyngeal swab samples were tested for SARSCoV-2 PCR yielded negative results, and the blood sample tested for SARS CoV-2 IgM + IgG antibody yielded positive results. There was no pathological sign on chest CT. A little amount of free liquid was detected in the pelvic region and among some parts of small intestine on abdomen CT. After obtaining blood, urine, and stool samples for cultures, 


\begin{tabular}{|c|c|c|c|c|c|c|c|c|c|}
\hline 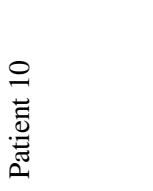 & 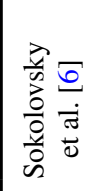 & 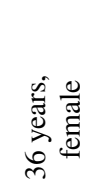 & 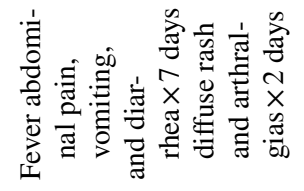 & そ̋ & 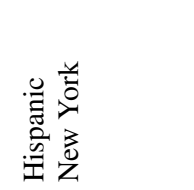 & 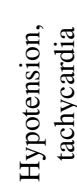 & $\stackrel{\overbrace{}}{\stackrel{ \pm}{ \pm}}$ & 之o & 文 \\
\hline & 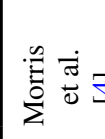 & 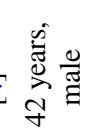 & 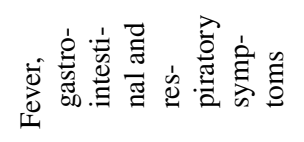 & $\begin{array}{l}\stackrel{\overrightarrow{0}}{0} \\
\text { ठे }\end{array}$ & 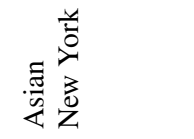 & そ & $\underset{I}{\stackrel{2}{I}}$ & 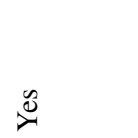 & m \\
\hline & $\sum_{i}^{0} \frac{\dot{\sigma}}{d}=$ & 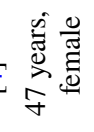 & 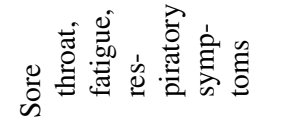 & ஜ̋ & 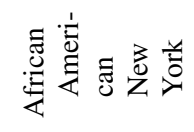 & 之 & 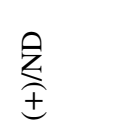 & 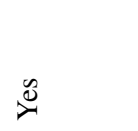 & 之 \\
\hline 牙 & 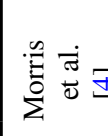 & 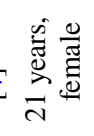 & 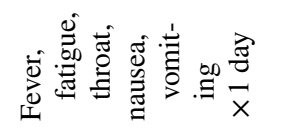 & 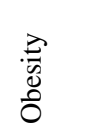 & 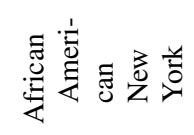 & 学 & $\underset{ \pm}{\stackrel{Ð}{ \pm}}$ & $\stackrel{\circlearrowright}{\circlearrowright}$ & $\ddot{\lambda}$ \\
\hline 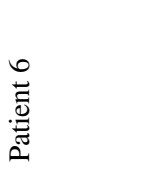 & 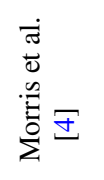 & 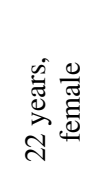 & 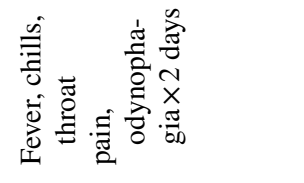 & 苂 & 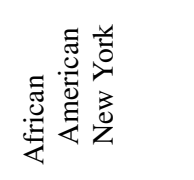 & z & 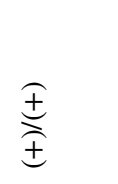 & ż & 之 \\
\hline 殸 & $\stackrel{\infty}{\dot{E}} \dot{\bar{\sigma}}$ & 常 & 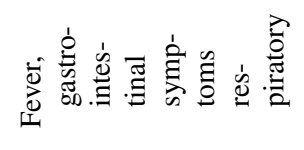 & 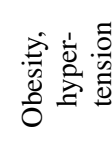 & 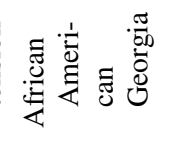 & 文 & 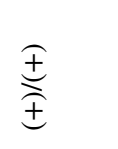 & $\triangleq$ & $\vec{\gamma}$ \\
\hline 离 & 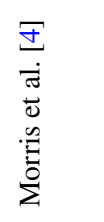 & 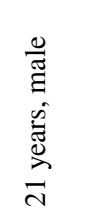 & 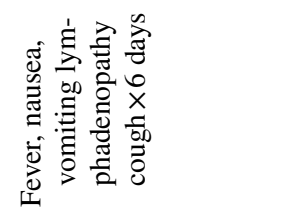 & $\begin{array}{l}\stackrel{2}{0} \\
\text { ठ̊ } \\
0\end{array}$ & 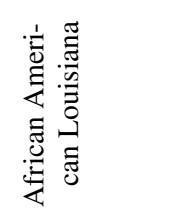 & 合 & $\stackrel{\overparen{I}}{\stackrel{I}{I}}$ & z & 文 \\
\hline 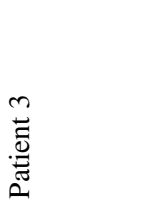 & 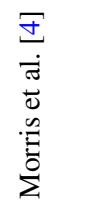 & 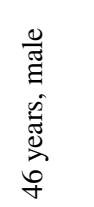 & 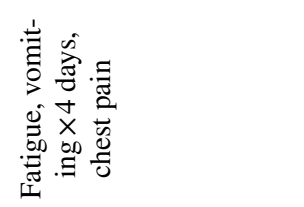 & $\begin{array}{l}\text { त्रे } \\
\text { o } \\
0\end{array}$ & 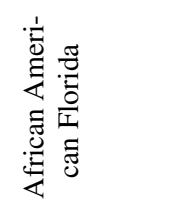 & 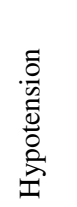 & $\stackrel{\overparen{I}}{\stackrel{I}{I}}$ & 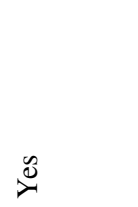 & 文 \\
\hline 茂 & 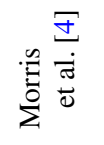 & 离 & 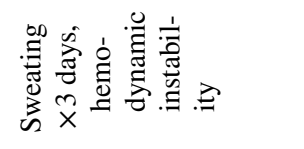 & $\begin{array}{l}\check{0} \\
\check{z}\end{array}$ & 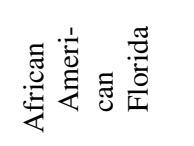 & 合 & $\underset{ \pm}{\stackrel{Ð}{ \pm}}$ & ż & 之 \\
\hline D & 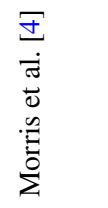 & 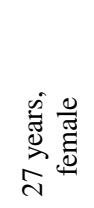 & 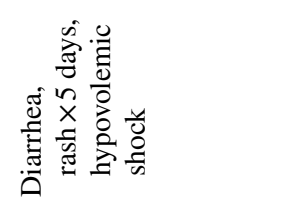 & 气̆ & 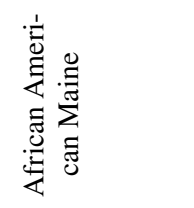 & そ & $\stackrel{\overparen{I}}{\stackrel{I}{I}}$ & z & 之 \\
\hline $\begin{array}{l}\sim \\
\tilde{D} \\
\tilde{z}\end{array}$ & & 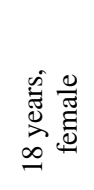 & 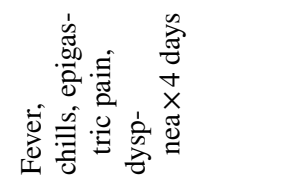 & ஜัँ & 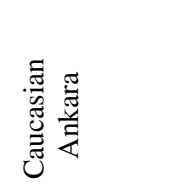 & 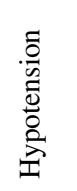 & $\stackrel{\overparen{I}}{\stackrel{I}{I}}$ & 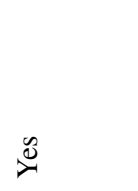 & 8 \\
\hline 离 & & 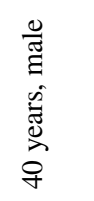 & 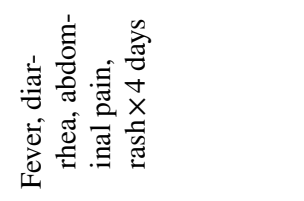 & $\begin{array}{l}0 \\
\check{0} \\
z\end{array}$ & 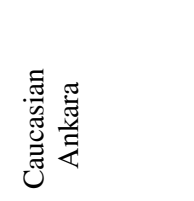 & 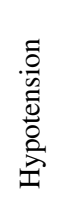 & $\stackrel{\overparen{I}}{\stackrel{I}{I}}$ & . & $\ddot{\sim}$ \\
\hline 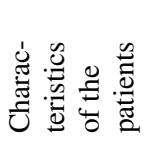 & 离 & 京 & 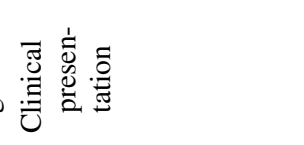 & 峞 & 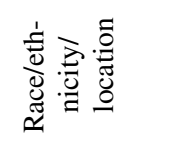 & 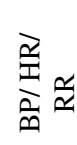 & 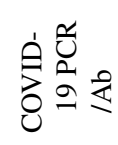 & 总主 & 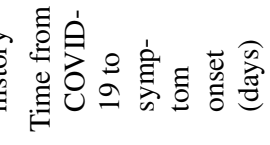 \\
\hline
\end{tabular}




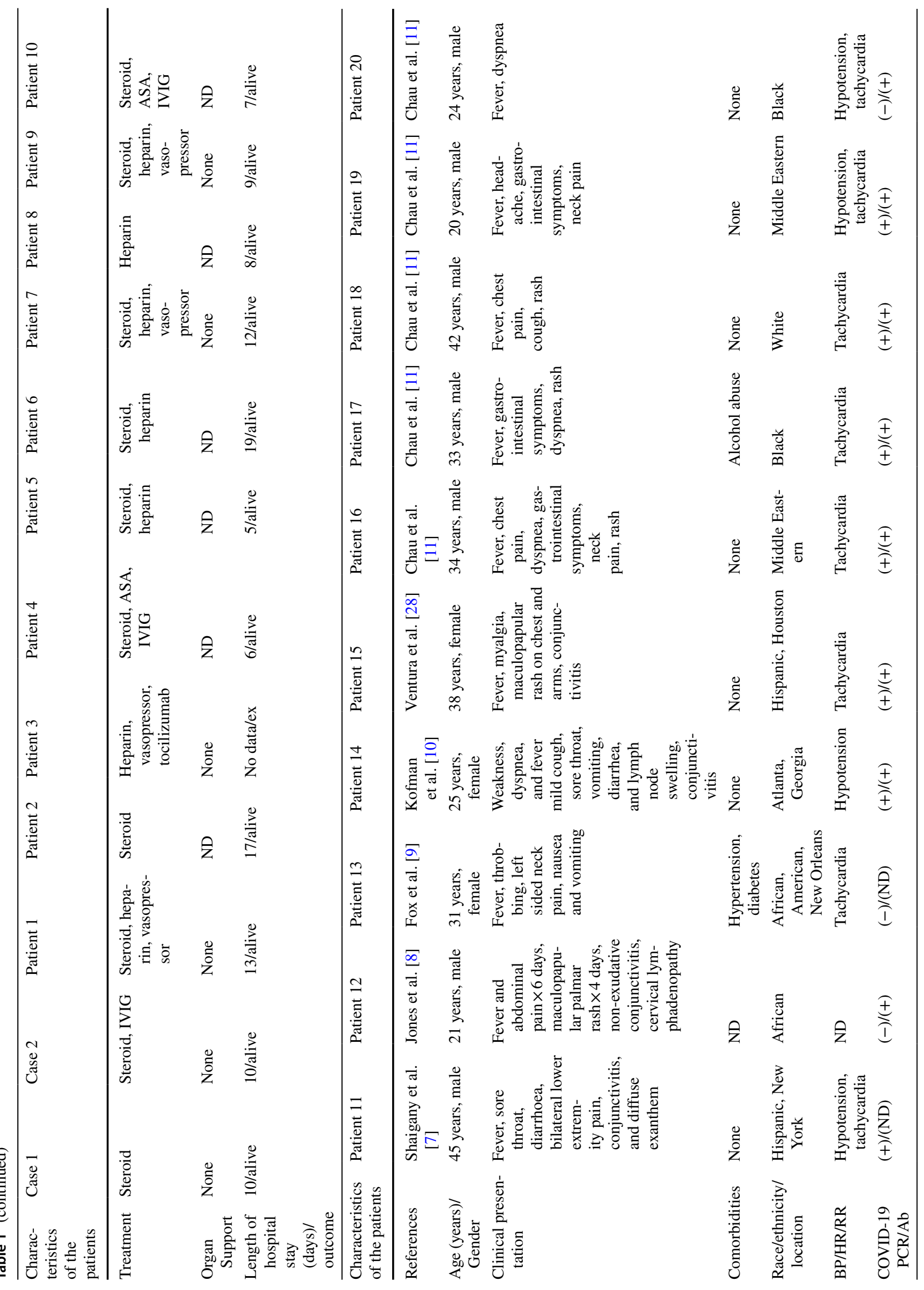




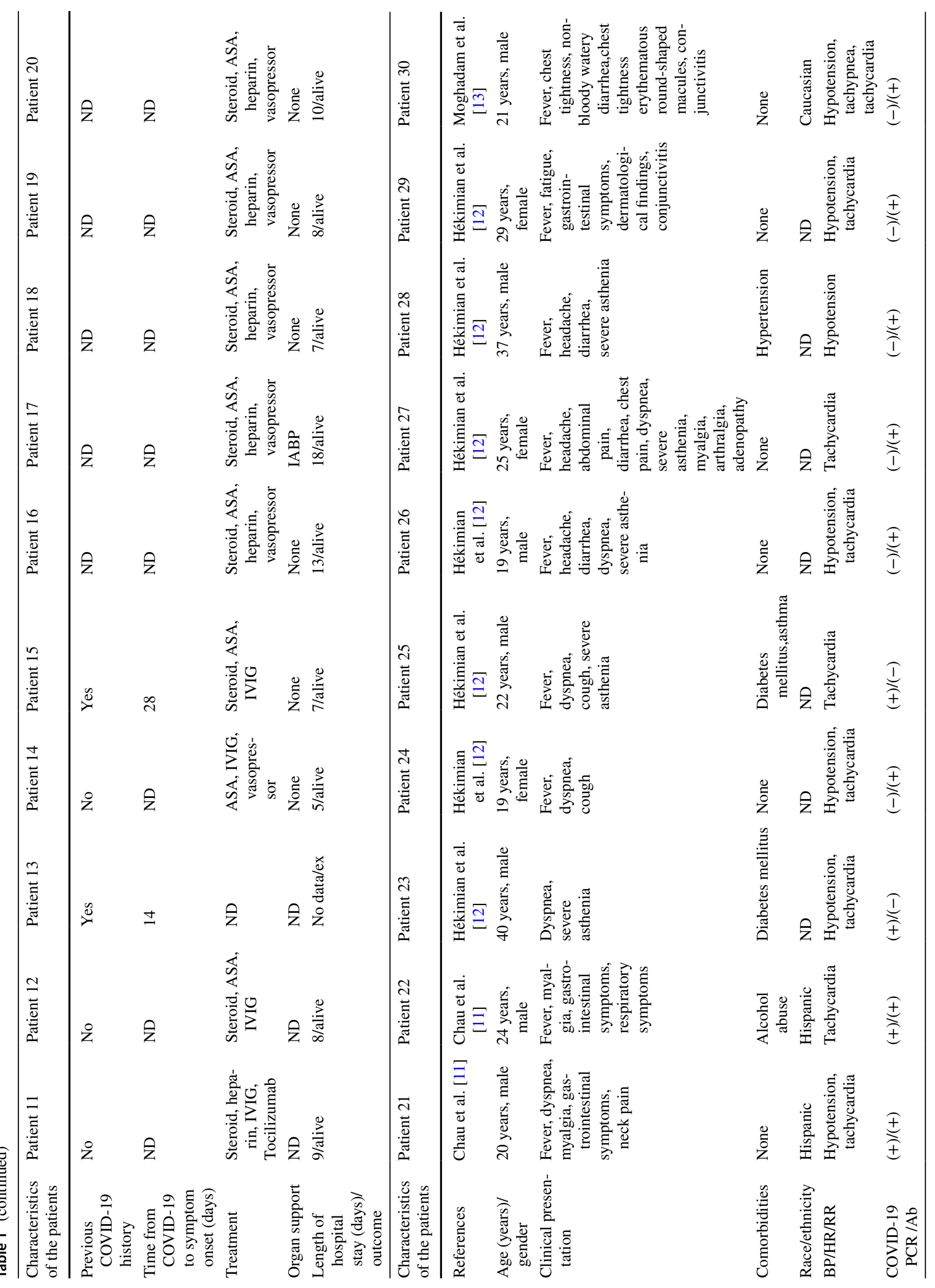




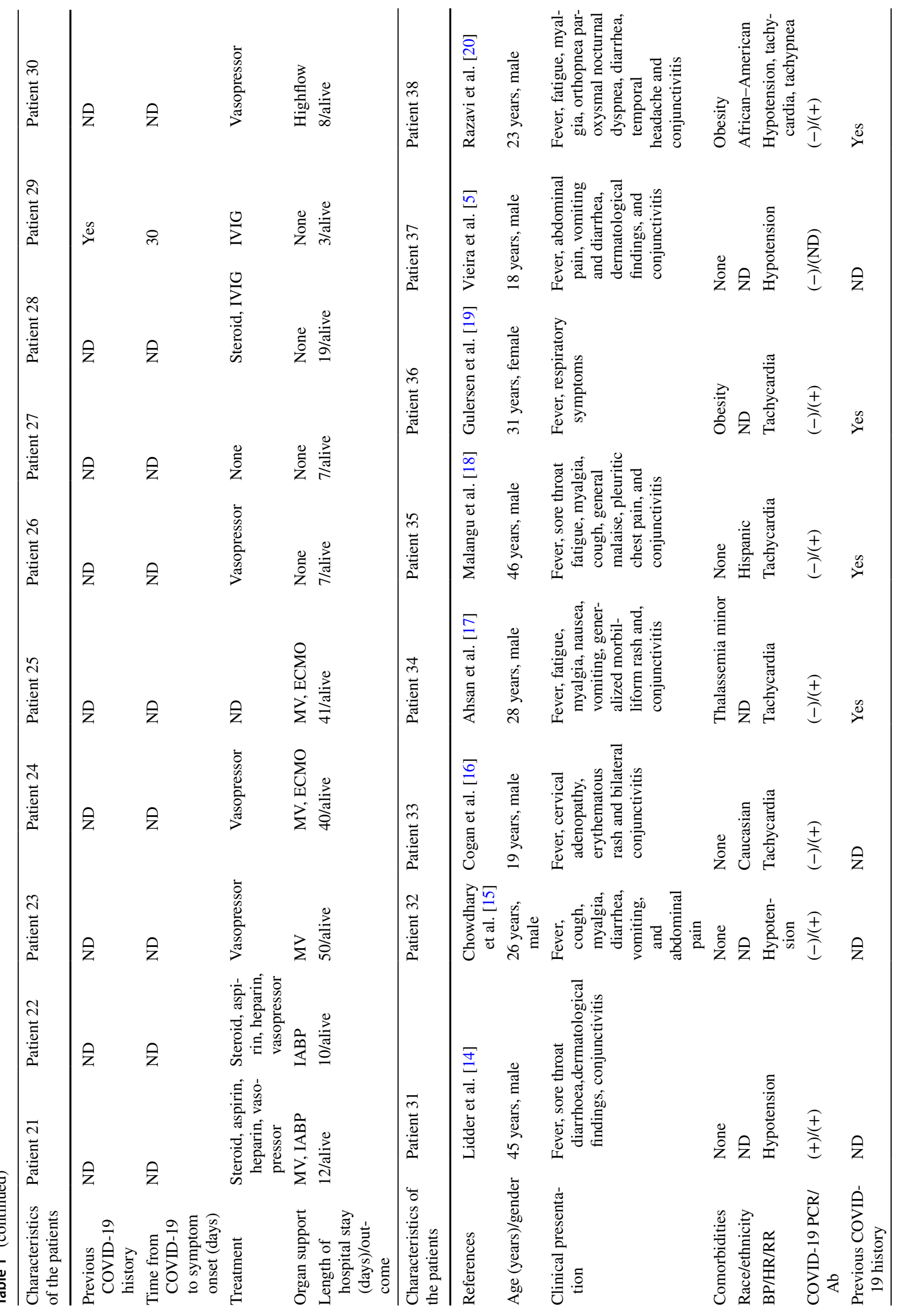




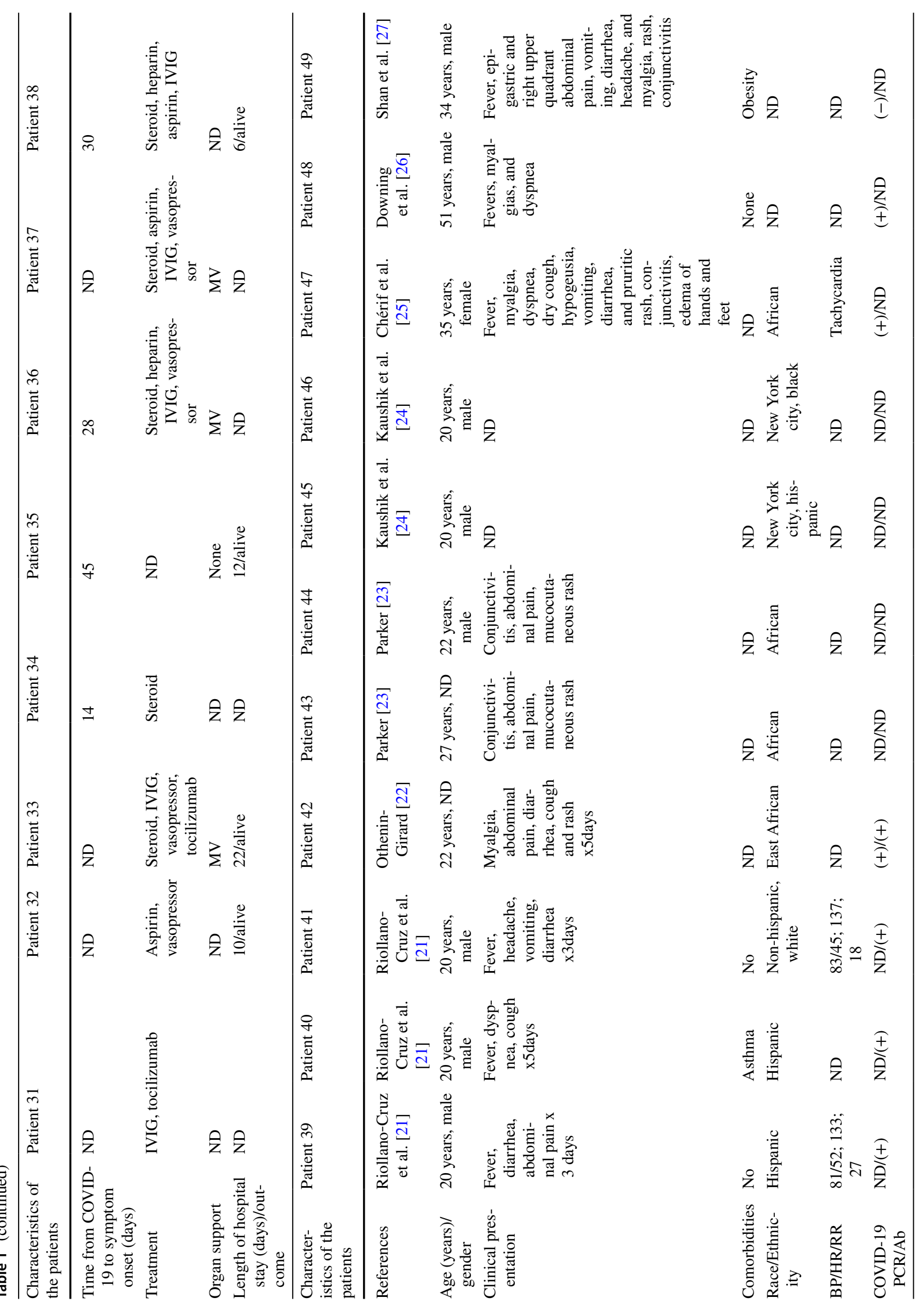




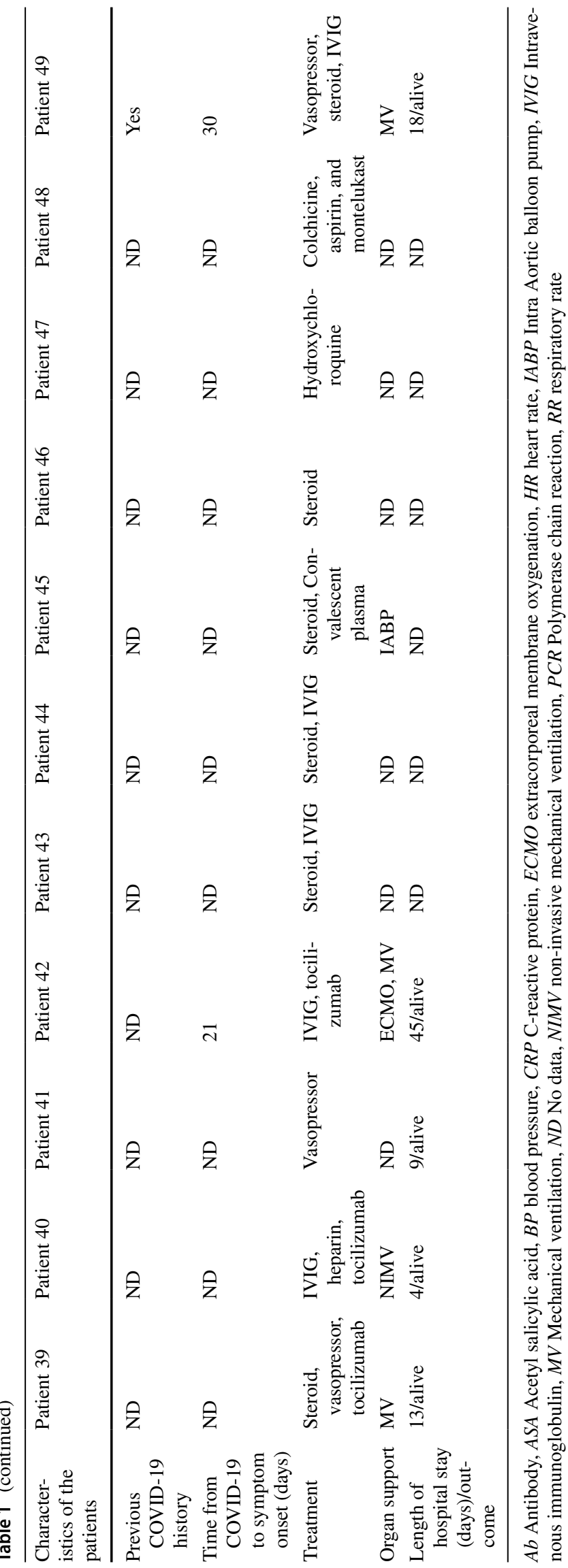

empirical ceftriaxone $2 \mathrm{gr} /$ day was started. On the follow up, hypotension, tachycardia, and hypoxia developed on the first day of treatment, and procalcitonin, troponin, and pro-BNP levels were found increased. A hydration therapy with crystalloids was given and the ceftriaxone therapy was escalated to broader spectrum antibiotics. The electrocardiography (ECG) showed sinus tachycardia. The examination of transthoracic echocardiography (TTE) revealed no pathologic findings on the cardiac valve. Global hypokinesis was detected and ejection fraction was $45 \%$. The diagnosis of MIS-A was considered according to these clinical and laboratory findings. Methyl prednisolone $250 \mathrm{mg} /$ day intravenously for 3 days and IVIG 20 gr/day for 5 days, and low molecular weight heparin as an anticoagulant prophylaxis, beta blocker and angiotensin converting enzyme (ACE) inhibitor were given to the patient. Antibiotic treatment was discontinued on the 4th day of treatment when the culture tests resulted in negative. The blood oxygen saturation was detected as $86 \%$ and the need of oxygen support increased (4 L with nasal cannula) on the second day of admission. Intravenous furosemide treatment was given since the control chest radiography revealed pulmonary edema. The fever decreased after the first day of methylprednisolone and IVIG treatment, but the need of slightly supplemental oxygen therapy was continued for 3 days. Thereafter, the patient had a significant improvement in respiratory effort capacity on the 3rd day of pulse steroid and IVIG treatment, and abdominal pain began to regress. The dose of the methylprednisolone was reduced and completed to 10 days $(250 \mathrm{mg}$ pulse steroid for 3 days, $80 \mathrm{mg} /$ day for 3 days, and $40 \mathrm{mg}$ /day for 4 days). The control TTE, on the follow up, revealed no deterioration in the previous findings. The furosemide and supplemental oxygen therapy were stopped on the fifth day. After the sixth day of the therapy, she was able to move without help. After 10 days of follow-up, she was discharged from hospital fully recovered. On the follow-up visit on day 15 after discharge, he was completely healthy.

\section{Search strategy}

The PubMed, Scopus, and Web of Science Core Collection databases were searched for published case reports of MIS in adults and adolescents aged $\geq 18$ years-old from January 2020 to February 2021. The following keywords were used for literature search: 'multisystem inflammatory syndrome in adults and COVID-19', 'multisystem inflammatory syndrome in adolescents and COVID-19' and 'Kawasaki-like syndrome in adults and COVID-19'. After exclusion of irrelevant articles, a total of 11 adolescent cases of MIS-C aged 18-20 years and 38 cases of MIS-A were reviewed [4-28]. The reports regarding $\geq 18$-year-old adolescents and adult patients diagnosed with multisystem inflammatory disease 


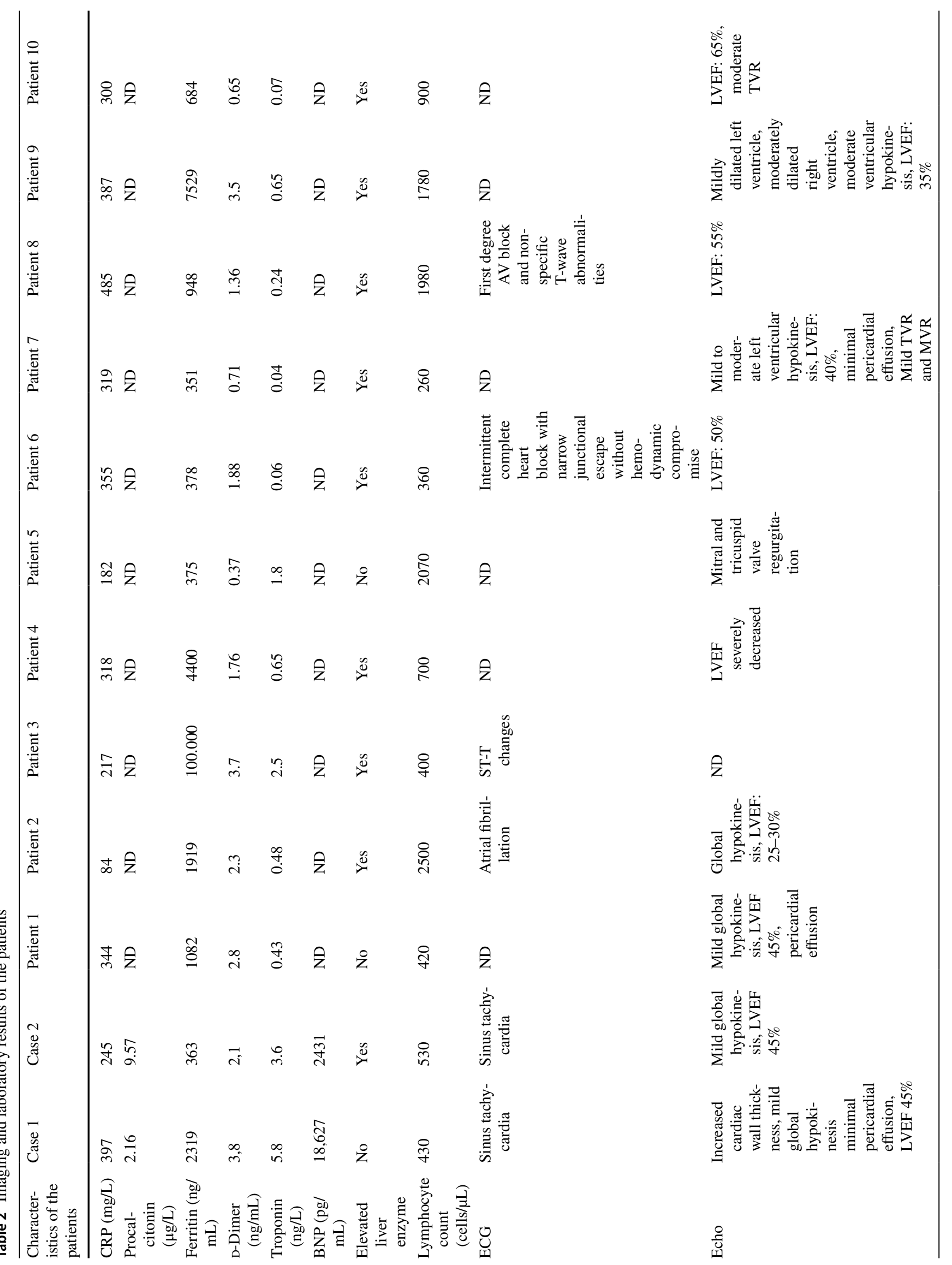




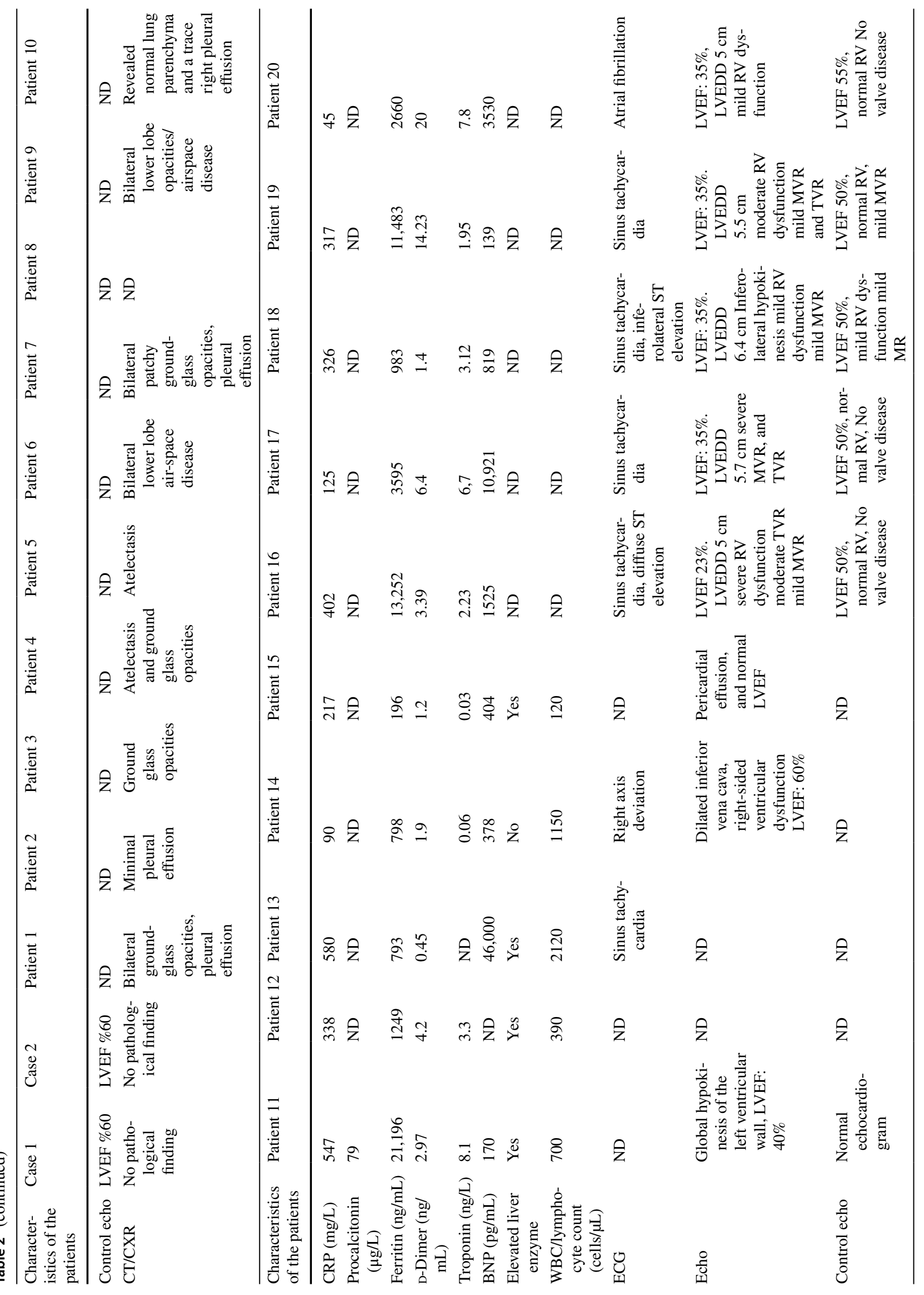




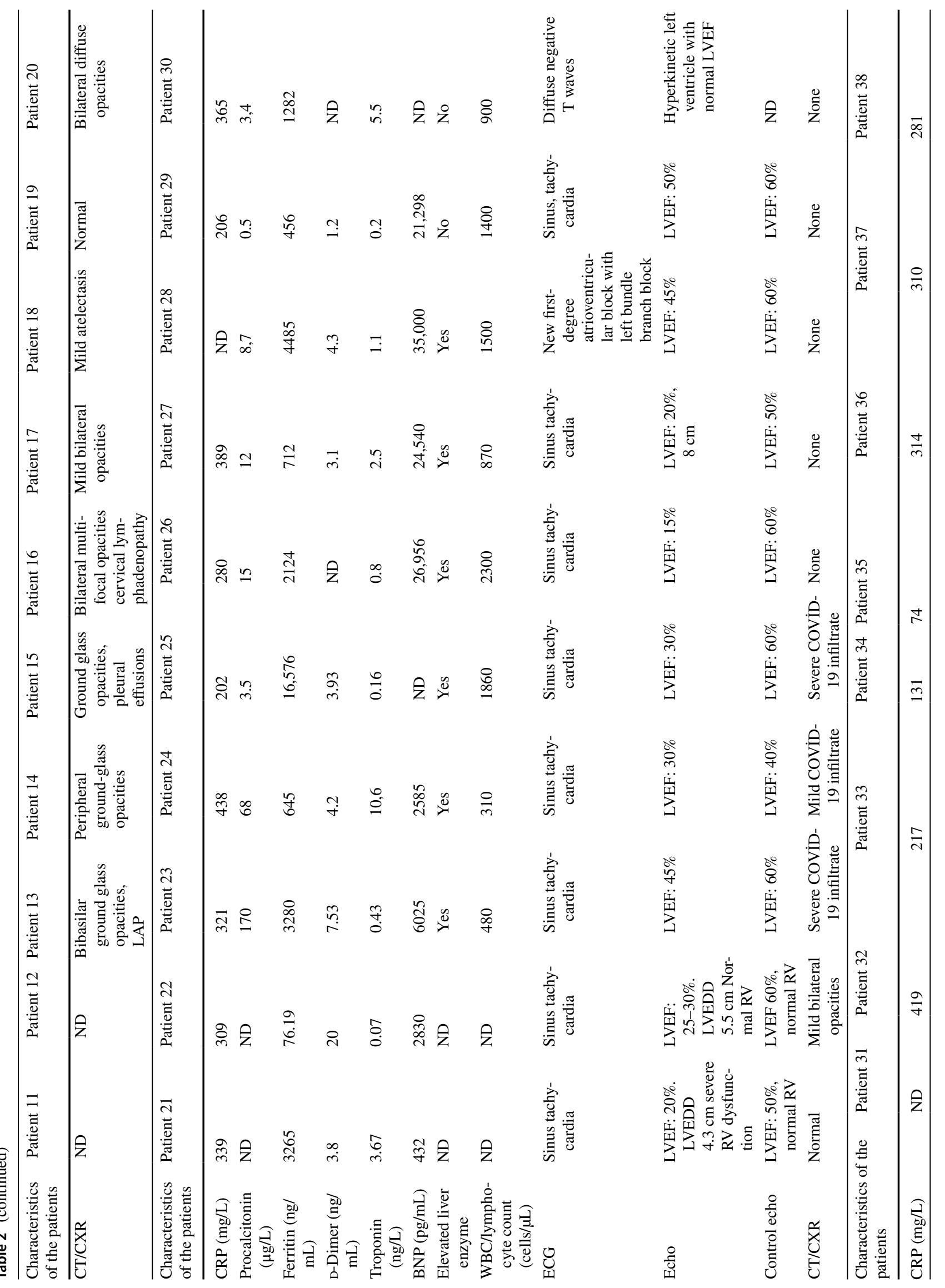




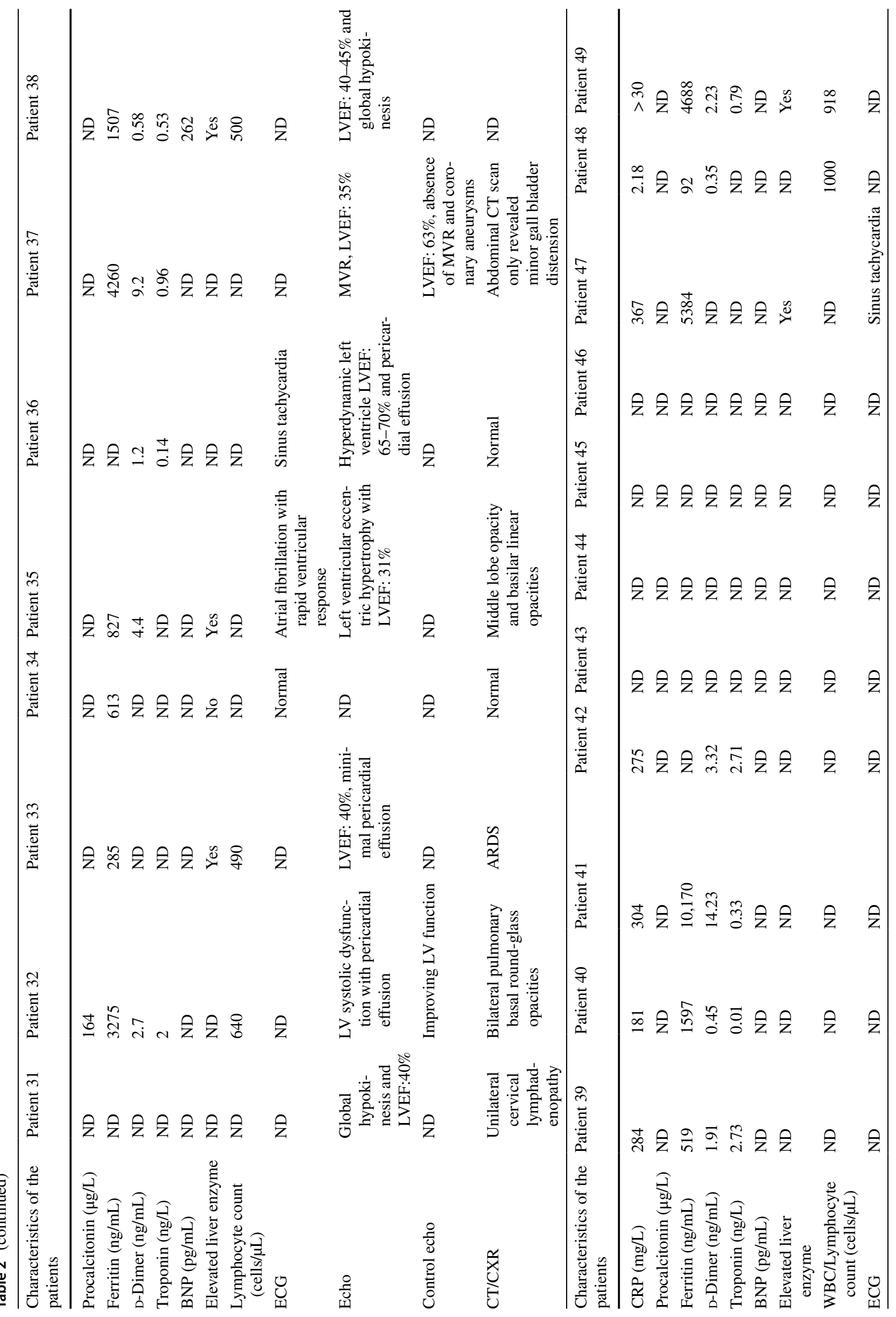


were selected and included into this review to increase the awareness of the clinicians providing care in these age groups.

\section{Discussion}

There have been 49 case reports of a MIS in adults and adolescents aged $\geq 18$ years-old since June 2020 . The Centers for Disease Control and Prevention (CDC) published a report in October 2020 to define the clinical and laboratory characteristics and the treatment modalities used in reported and published case series of MIS-A [4]. There is a lack of clear evidence on immune-pathophysiology of the syndrome, but an antibody-related immune response may be responsible. It is thought as a post-infectious syndrome rather than an infection in acute stage of development $[4,5]$. Although there is a heterogeneity of symptoms and findings, gastrointestinal symptoms such as abdominal pain, diarrhea, vomiting, and myocarditis, fever, hypotension via capillary leak syndrome, and shock are the predominant ones. The World Health Organization (WHO) and CDC categorized the multisystem inflammatory syndrome according to the age of the patients. WHO accepted patients aged $0-19$ years with the defined characteristic features as MIS-C, whilst CDC accepted those $<21$ years-old in this group. The main determinative characteristics of the syndrome used in case definitions are the followings $[4,5]$ :

(1) Increase in inflammatory biomarkers (CRP, ferritin, D-dimer etc.) accompanying fever;

(2) Laboratory confirmation of recent COVID-19 infection (with positive test results of RT-PCR and/or SARSCoV-2 antibody), within previous 12 weeks before the symptom onset;

(3) The exclusion of other specific causative microbial agents;

(4) The lack of the severe respiratory illness (to exclude the effect of tissue hypoxia as the cause of the organ dysfunction);

(5) In addition to the above criterions, the two of the following features are necessary;

- $\quad$ Rash \pm non-purulent conjunctivitis \pm mucocutaneus inflammation findings,

- Low blood pressure \pm shock,

- Findings of cardiac involvement such as myocarditis, valvulitis or pericarditis, abnormalities on echocardiography or laboratory tests (increased proBNP, troponin),

- Clinical or laboratory findings of coagulation abnormalities (elevated D-dimer, prothrombin time, active partial thromboplastin time) and/or liver injury, 
- The new onset gastrointestinal symptoms such as abdominal pain, vomiting, diarrhea.

The present cases had a history of positive test results for SARS-CoV-2 PCR, 23 days and 2 months ago, respectively. The RT-PCR tests for SARS-CoV-2 were repeated and resulted negative, whilst the tests of SARS-CoV-2 IgM + IgG resulted positive. Of the previously reported 49 cases, 35 had positive SARS-CoV-2 antibody results, 18 had only positive antibody test results, and 18 had both positive SARS-CoV-2 PCR and antibody results. The five of the remained 10 cases were PCR positive, and three cases were PCR negative and antibody test were not performed. The results of antibody and PCR tests were not given for previously reported four patients (Table 1) [4-28]. The interval between COVID-19 and the development of MIS-A symptoms reported previously as about $2-5$ weeks [4]. When the time interval from positive PCR results to symptoms of MIS was evaluated, it was determined mean $31.25 \pm 13.03$ days. Hékimian et al. reported 11 adolescent and adult patients with MIS, who were presented with fever, abdominal pain, nausea, vomiting, various mucocutaneous findings, and symptoms indicating myocardial dysfunction accompanied by severe inflammation. They reported normalization of EF in $54.5 \%$ of the patients and improvement in about 1 week in $36.4 \%$ of the patients whilst one of the patients died despite the implementation of extra-corporeal membrane oxygenation (ECMO) [13]. Both of the present cases had fever, abdominal pain, hypotension, and myocarditis in addition to elevated inflammation biomarkers. Additionally, the patient with the diagnosis of MIS-A had terminal ileitis and rash. The EF was normalized in both patients on the control echocardiography performed at the end of the therapy on the 10th day of admission.

A total of 51 patients with MIS-A were analyzed and the mean age was determined as $29.4 \pm 10$ years. Cardiovascular abnormalities such as global hypokinesis and decreased left ventricular ejection fraction (LVEF) were the most frequently reported findings $(82.4 \%, 42 / 51)$. The other prominent symptoms were as follows: $80.4 \%$ fever, $72.5 \%$ gastrointestinal symptoms (abdominal pain, nausea, vomiting and, diarrhea), $54.9 \%$ respiratory symptoms (cough and, dyspnea), and $36 \%$ myalgia. When the relevant findings of the cases were evaluated, requirement of vasopressor therapy for hypotension was detected in $44 \%$ of the patients. The dermatological findings (erythematous rash, periorbital rash, annular targeted lesions etc.) were defined in $39.2 \%$ of the patients. Conjunctival findings, such as non-exudative conjunctivitis, were determined in $35.3 \%$ of the patients. Lymphadenopathy was detected in $17.6 \%$ of the patients. Most of the patients with MIS-A had higher levels of inflammatory biomarkers such as CRP, D-dimer, and ferritin. The mean level for CRP was $293.7 \pm 119.3 \mathrm{mg} / \mathrm{L}$ and the mean level for lymphocyte was 999 cell $/ \mu \mathrm{L}( \pm 119.3)$, the median level for ferritin was $1265 \mu \mathrm{g} / \mathrm{L}(21-100.000)$ and the median level for D-dimer was $2.8 \mu \mathrm{g} / \mathrm{L}(0.35-20)$ (Table 2) [4-28].

Since MIS-A is an emergent condition and may have a risk of rapidly worsening clinical progression, patients with clinical suspicion should be treated promptly.

The American College of Rheumatology published a diagnosis and treatment guideline for pediatric patients diagnosed with MIS-C associated with SARS-CoV-2 [29]. The pulse steroid treatment with methylprednisolone $20-30 \mathrm{mg} / \mathrm{kg}$ per day, for $1-3$ days up to $1 \mathrm{gr} /$ day, then tapering doses $(2 \mathrm{mg} / \mathrm{kg}$ per day, maximum $60 \mathrm{mg} /$ day $)$ were recommended previously in moderate and severe cases [30]. Additionally, it was reported that a combination of IVIG and steroid therapy may be more effective for symptom relief than IVIG monotherapy in Kawasaki Disease (KD), which has pathophysiologic characteristics similar to MIS-C [30]. For MIS-C patients, supportive care in addition to therapy against underlying inflammatory process with IVIG, steroid, aspirin, anticoagulant treatment are recommended [31]. However, there exist no widely accepted guidelines yet for the diagnosis and treatment for MIS-A. Treatment modalities have been extrapolated from suggested therapies for MIS-C since the syndrome is similar. Each center implements its own treatment protocol on the basis of reported cases. The present case-based review revealed that $60.8 \%$ (31/51) of the patients were treated with steroid, and $37.3 \%$ (19/51) with IVIG. The tocilizumab treatment was given to only $13.7 \%$ (7/51) of the patients. When the disease severity was evaluated, it was observed that $19.6 \%(10 / 51)$ of the patients required respiratory support with mechanical ventilation, $7.8 \%(4 / 51)$ required intra-aortic balloon pump (IABP), and $5.9 \%(3 / 51)$ required ECMO [4, 6-28]. Two of the reported patients died during the follow-up period $[4,10]$. In the present cases, a combination of IVIG and pulse methylprednisolone treatment was proposed fast clinical resolution. For quick intervention, we started antibiotic treatment along with steroid, anticoagulant, and IVIG treatments without waiting the exclusion of other infectious agents.

As a consequence, it is important to start the treatment immediately by rapid diagnosis and careful monitoring. MIS-A may be a quite serious clinical condition that needs urgent and effective treatment and may result in worse outcomes without appropriate management. IVIG and pulse steroid treatments are the effective options on clinical improvement.

Author contributions Conception and design of the work: $\mathrm{AB}$ and HB. The acquisition, analysis, or interpretation of data for the work: all authors. Drafting the work or revising it critically for important 
intellectual content: all authors. Final approval of the version to be published: all authors. Agreement to be accountable for all aspects of the work in ensuring that questions related to the accuracy or integrity of any part of the work are appropriately investigated and resolved: all authors. We acknowledge Osman Topac for performing language editing.

Funding This research did not receive any specific grant from funding agencies in the public, commercial, or not-for-profit sectors.

Data availability Possible.

\section{Declarations}

Conflict of interest The authors declare that they have no known competing interests.

Informed consent It was obtained from the patients for publication of the present case report.

\section{References}

1. Kabeerdoss J, Pilania RK, Karkhele R, Kumar TS, Danda D, Singh S (2020) Severe COVID-19, multisystem inflammatory syndrome in children, and Kawasaki disease: immunological mechanisms, clinical manifestations and management. Rheumatol Int. https://doi.org/10.1007/s00296-020-04749-4

2. Feldstein LR, Rose EB, Horwitz SM, Collins JP, Newhams MM, Son MBF, Newburger JW, Kleinman LC, Heidemann SM, Martin AA (2020) Multisystem inflammatory syndrome in US children and adolescents. N Engl J Med 383(4):334-346. https://doi.org/ 10.1056/NEJMoa2021680

3. Riphagen S, Gomez X, Gonzalez-Martinez C, Wilkinson N, Theocharis P (2020) Hyperinflammatory shock in children during COVID-19 pandemic. Lancet 395(10237):1607-1608. https://doi. org/10.1016/S0140-6736(20)31094-1

4. Morris SB, Schwartz NG, Patel P, Abbo L, Beauchamps L, Balan S, Lee EH, Paneth-Pollak R, Geevarughese A, Lash MK (2020) Case series of multisystem inflammatory syndrome in adults associated with SARS-CoV-2 infection-United Kingdom and United States, March-August 2020. Morb Mortal Wkly Rep 69(40):1450. https://doi.org/10.15585/mmwr.mm6940e1

5. Jiang L, Tang K, Levin M, Irfan O, Morris SK, Wilson K, Klein JD, Bhutta ZA (2020) COVID-19 and multisystem inflammatory syndrome in children and adolescents. Lancet Infect Dis 20(11):e276-e288. https://doi.org/10.1016/S1473-3099(20) 30651-4

6. Vieira CB, Ferreira AT, Cardoso FB, Paulos JP, Germano N (2020) Kawasaki-like syndrome as an emerging complication of SARS-CoV-2 infection in young adults. Eur J Case Rep Intern Med 7(10):001886. https://doi.org/10.12890/2020_001886

7. Sokolovsky S, Soni P, Hoffman T, Kahn P, Scheers-Masters J (2021) COVID-19 associated Kawasaki-like multisystem inflammatory disease in an adult. Am J Emerg Med 39:253.e1-253.e2. https://doi.org/10.1016/j.ajem.2020.06.053

8. Shaigany S, Gnirke M, Guttmann A, Chong H, Meehan S, Raabe V, Louie E, Solitar B, Femia A (2020) An adult with Kawasakilike multisystem inflammatory syndrome associated with COVID19. Lancet 396(10246):e8-e10. https://doi.org/10.1016/S01406736(20)31526-9
9. Jones I, Bell LC, Manson JJ, Last A (2020) An adult presentation consistent with PIMS-TS. Lancet Rheumatol 2(9):e520-e521. https://doi.org/10.1016/S2665-9913(20)30234-4

10. Fox SE, Lameira FS, Rinker EB, Vander Heide RS (2020) Cardiac Endotheliitis and multisystem inflammatory syndrome after COVID-19. Ann Intern Med 173(12):1025-1027. https://doi.org/ 10.7326/L20-0882

11. Kofman AD, Sizemore EK, Detelich JF, Albrecht B, Piantadosi AL (2020) A young adult with COVID-19 and multisystem inflammatory syndrome in children (MIS-C)-like illness: a case report. Bmc Infect Dis 20:1. https://doi.org/10.1186/ s12879-020-05439-z

12. Chau VQ, Giustino G, Mahmood K, Oliveros E, Neibart E, Oloomi M, Moss N, Mitter SS, Contreras JP, Croft L (2020) Cardiogenic shock and hyperinflammatory syndrome in young males with COVID-19. Circ Heart Fail 13(10):007485. https://doi.org/ 10.1161/CIRCHEARTFAILURE.120.007485

13. Hékimian G, Kerneis M, Zeitouni M, Cohen-Aubart F, Chommeloux J, Bréchot N, Mathian A, Lebreton G, Schmidt M, Hié M (2020) Coronavirus disease 2019 acute myocarditis and multisystem inflammatory syndrome in adult intensive and cardiac care units. Chest. https://doi.org/10.1016/j.chest.2020.08.2099

14. Moghadam P, Blum L, Ahouach B, Radjou A, Lambert C, Scanvic A, Martres P, Decalf V, Begon E, Bachmeyer C (2021) Multisystem inflammatory syndrome with particular cutaneous lesions related to COVID-19 in a young adult. Am J Med 134(1):E36E37. https://doi.org/10.1016/j.amjmed.2020.06.025

15. Lidder AK, Pandit SA, Lazzaro DR (2020) An adult with COVID19 kawasaki-like syndrome and ocular manifestations. Am J Ophthalmol Case Rep 20:100875. https://doi.org/10.1016/j.ajoc.2020. 100875

16. Chowdhary A, Joy E, Plein S, Abdel-Rahman S-E-D (2020) Multisystem inflammatory syndrome in an adult with SARS-CoV-2 infection. Eur Heart J Cardiovasc Imaging. https://doi.org/10. 1093/ehjci/jeaa232

17. Cogan E, Foulon P, Cappeliez O, Dolle N, Vanfraechem G, De Backer D (2020) Multisystem inflammatory syndrome with complete kawasaki disease features associated with SARS-CoV-2 infection in a young adult. Case Rep Front Med. https://doi.org/ 10.3389/fmed.2020.00428

18. Ahsan T, Rani B (2020) A case of multisystem inflammatory syndrome post-COVID-19 infection in an adult. Cureus. https://doi. org/10.7759/cureus. 11961

19. Malangu B, Quintero JA, Capitle EM (2020) Adult inflammatory multi-system syndrome mimicking kawasaki disease in a patient with COVID-19. Cureus. https://doi.org/10.7759/cureus.11750

20. Gulersen M, Staszewski C, Grayver E, Tam HT, Gottesman E, Isseroff D, Rochelson B, Bonanno C (2021) Coronavirus Disease 2019 (COVID-19)-related multisystem inflammatory syndrome in a pregnant woman. Obstet Gynecol 137(3):418-422. https:// doi.org/10.1097/AOG.0000000000004256

21. Razavi AC, Chang JL, Sutherland A, Niyogi A, Ménard GE (2020) A 23-year-old man with multisystem inflammatory syndrome after mild COVID-19. J Invest Med High Impact Case Rep 8:2324709620974200. https://doi.org/10.1177/2324709620 974200

22. Riollano-Cruz M, Akkoyun E, Briceno-Brito E, Kowalsky S, Reed J, Posada R, Sordillo EM, Tosi M, Trachtman R, PanizMondolfi A (2021) Multisystem inflammatory syndrome in children related to COVID-19: a New York City experience. J Med Virol 93(1):424-433. https://doi.org/10.1002/jmv.26224

23. Othenin-Girard A, Regamey J, Lamoth F, Horisberger A, Glampedakis E, Epiney J-B, Kuntzer T, de Leval L, Carballares M, Hurni C-A (2020) Multisystem inflammatory syndrome with refractory cardiogenic shock due to acute myocarditis and 
mononeuritis multiplex after SARS-CoV-2 infection in an adult. Swiss Med Wkly 150:w20387. https://doi.org/10.4414/smw.2020. 20387

24. Parker A, Louw E, Lalla U, Koegelenberg C, Allwood B, Rabie H, Sibeko S, Taljaard J, Lahri S (2020) Multisystem inflammatory syndrome in adult COVID-19 patients. S Afr Med J 110(10):957958. https://doi.org/10.7196/SAMJ.2020.v110i10.15244

25. Kaushik S, Aydin SI, Derespina KR, Bansal PB, Kowalsky S, Trachtman R, Gillen JK, Perez MM, Soshnick SH, Conway EE Jr (2020) Multisystem inflammatory syndrome in children associated with severe acute respiratory syndrome coronavirus 2 infection (MIS-C): a multi-institutional study from New York City. J Pediatr 224:24-29. https://doi.org/10.1016/j.jpeds.2020.06.045

26. Chérif MY, de Filette JM, André S, Kamgang P, Richert B, Clevenbergh P (2020) Coronavirus disease 2019-related Kawasakilike disease in an adult: a case report. JAAD Case Rep 6(8):780782. https://doi.org/10.1016/j.jdcr.2020.06.023

27. Downing S, Chauhan V, Chaudry IH, Galwankar S, Sharma P, Stawicki SP (2020) Colchicine, aspirin, and montelukast: a case of successful combined pharmacotherapy for adult multisystem inflammatory syndrome in COVID-19. J Global Infect Dis 12(2):47-93. https://doi.org/10.4103/jgid.jgid_86_20

28. Shan Y, Dalal V, Nahass RG, Rodricks MB, Teichman AL (2020) Multisystem inflammatory syndrome in an adult after COVID-19. Infect Dis Clin Pract 28(6):e28-e29. https://doi.org/10.1097/IPC. 0000000000000938

29. Henderson LA, Canna SW, Friedman KG, Gorelik M, Lapidus SK, Bassiri H, Behrens EM, Ferris A, Kernan KF, Schulert GS
(2020) American College of Rheumatology Clinical Guidance for Multisystem Inflammatory Syndrome in Children Associated With SARS-CoV-2 and Hyperinflammation in Pediatric COVID19: Version 1. Arthritis Rheumatol 72(11):1791-1805. https://doi. org/10.1002/art.41454

30. Jonat B, Gorelik M, Boneparth A, Geneslaw AS, Zachariah P, Shah A, Broglie L, Duran J, Morel KD, Zorrilla M (2020) Multisystem inflammatory syndrome in children associated with Coronavirus disease 2019 in a Children's Hospital in New York City: patient characteristics and an institutional protocol for evaluation, management, and follow-up. Pediatr Crit Care Med 22(3):e178191. https://doi.org/10.1097/PCC.0000000000002598

31. Dove ML, Jaggi P, Kelleman M, Abuali M, Ang JY, Ballan W, Basu SK, Campbell MJ, Chikkabyrappa SM, Choueiter NF, Clouser KN, Corwin D, Edwards A, Gertz SJ, Ghassemzadeh R, Jarrah RJ, Katz SE, Knutson SM, Kuebler JD, Lighter J, Mikesell C, Mongkolrattanothai K, Morton T, Nakra NA, Olivero R, Osborne CM, Panesar LE, Parsons S, Patel RM, Schuette J, Thacker D, Tremoulet AH, Vidwan NK, Oster ME (2021) Multisystem inflammatory syndrome in children: survey of protocols for early hospital evaluation and management. J Pediatr. 229:3340. https://doi.org/10.1016/j.jpeds.2020.10.026

Publisher's Note Springer Nature remains neutral with regard to jurisdictional claims in published maps and institutional affiliations. 